\title{
Molecular dynamics investigation of mixed-alkali borate glasses: Short-range order structure and alkali-ion environments
}

\author{
A. Vegiri, C.-P. E. Varsamis, ${ }^{*}$ and E. I. Kamitsos \\ Theoretical and Physical Chemistry Institute, National Hellenic Research Foundation, \\ 48 Vassileos Constantinou Avenue, 11635 Athens, Greece
}

(Received 14 May 2009; published 2 November 2009)

\begin{abstract}
Structural properties of mixed-alkali borate glasses, $0.3\left[(1-x) \mathrm{Li}_{2} \mathrm{O}-x \mathrm{Cs}_{2} \mathrm{O}\right]-0.7 \mathrm{~B}_{2} \mathrm{O}_{3}$ and $0.3\left[(1-x) \mathrm{Li}_{2} \mathrm{O}-x \mathrm{Na}_{2} \mathrm{O}\right]-0.7 \mathrm{~B}_{2} \mathrm{O}_{3}$, have been studied by molecular dynamics simulations at $T=300 \mathrm{~K}$ and for several values of the alkali mixing parameter, $x$, to explore structural foundations of the mixed-alkali effect (MAE). The short-range order (SRO) structure was found to consist of borate tetrahedra, $\mathrm{B} \varnothing_{4}^{-}$, and of neutral, $\mathrm{B} \varnothing_{3}$, and charged, $\mathrm{B} \varnothing_{2} \mathrm{O}^{-}$, triangular units $\left[\varnothing=\right.$ bridging oxygen atom]. The abundance of $\mathrm{B} \varnothing_{4}^{-}$units was found to decrease from $\mathrm{Li}$ to $\mathrm{Cs}$ and to exhibit negative deviation from linearity in Li-Cs glasses. However, no appreciable change in SRO structure was detected in mixed Li-Na glasses. Even though alkali metal $(M)$ ions occupy in mixed glasses sites, i.e., coordination environments with $\mathrm{O}$ atoms, similar to those formed in single alkali borates, mixing was found to affect the $M$-O bonding properties of dissimilar alkalis in an opposite manner. Thus, for both systems investigated here the Li ion-coordination environment was found to become better defined and the Li-O interactions to strengthen upon alkali mixing, whereas the Cs-O and Na-O interactions become progressively weakened. The origin of these trends was traced to cationic environments formed around nonbridging oxygen (NBO) atoms in glass; it was found that the dominant cation configurations around NBOs consist of dissimilar cations in mixed-alkali glasses. The formation of dissimilar ion pairs affects by polarization effects the bonding and vibrational properties of metal ions in their oxide sites. This was demonstrated for Li-Cs glasses by both experimental and calculated far infrared spectra, where the metal ion-oxide site vibrations are strongly active. It was discussed that the preference of unlike-alkali ion pairing around NBOs and the consequent drastic reduction in the number of NBOs that sense like-cations could provide a structural explanation for the MAE.
\end{abstract}

DOI: 10.1103/PhysRevB.80.184202

PACS number(s): 61.43.Fs, 71.55.Jv, 02.70.Ns

\section{INTRODUCTION}

The mixed-alkali effect (MAE) presents an ongoing challenge in glass science. This effect has been associated with the nonlinear variation in glass properties with composition when two dissimilar alkali ions are present in the glass matrix. The MAE is manifested mainly by properties that depend directly or indirectly on ionic mobility such as electrical conductivity, ionic diffusion, internal friction, viscosity, and glass transition temperature, ${ }^{1-5}$ while other bulk properties including molar volume, elastic moduli, and refractive index either vary linearly or show small deviations from linearity with alkali mixing. ${ }^{6,7}$

Early models on the MAE have proposed that interactions between dissimilar cations reduce their mobility, and, thus, affect strongly glass dynamic properties. ${ }^{8-13}$ Such interactions are thought to be associated with network-mediated "pairs" of dissimilar alkali ions, which are energetically favored relative to pairs of similar alkalis. Naturally, formation of pairs or clustering of unlike alkalis will affect their local bonding characteristics through polarizations effects. In parallel, the glass network would need to reorganize its local structure around dissimilar alkali ions in order to meet the new coordination requirements imposed by the presence of unlike cations in neighboring sites. Phenomena of this type would be manifested by progressive changes in cation-site interactions and in network local structures as the proportion of unlike alkalis varies in a mixed-alkali glass.

Far infrared spectroscopy has been employed to probe the effect of alkali mixing on the interactions between alkali ions and local sites in phosphate ${ }^{14}$ and silicate ${ }^{15}$ glasses. The key finding of these studies was that the vibration frequency of an alkali ion against its site (cage) is not affected by the introduction of a dissimilar alkali ion. These results were interpreted as indicating that the vibrationally significant local coordination and forces associated with a particular cation are unaffected by the addition of the second cation in the glass structure. This finding implies that each alkali ion forms its favorable site or range of sites which remains the same in single and mixed-alkali glasses of constant total alkali content. Besides far infrared spectroscopy, pulsed neutron scattering experiments, ${ }^{16}$ energy-dispersive $\mathrm{x}$-ray diffraction ${ }^{17}$ and $x$-ray absorption fine structure (XAFS) (Ref. 18) have also indicated that the local environment of an alkali ion is independent of the presence of a dissimilar alkali. Assuming that alkali ions retain the identity of their sites in the mixed-cation glass Maass and co-workers ${ }^{19}$ showed that this leads to significant site mismatch energy for ion transport and developed the dynamic structure model to explain the MAE. The essential feature of this model is that the ionic mobility is drastically reduced because conduction pathways are effectively blocked due to mismatch of the unlike-cation sites.

While the early far infrared measurements on mixedalkali glasses were performed by transmission on glass powders dispersed in low density polyethylene, ${ }^{14,15}$ advances during the last two decades in instrumentation, software and sampling techniques have facilitated specular reflectance measurements on bulk glasse ${ }^{20}$ in a broad and continuous 
frequency range, e.g., 30 to $5000 \mathrm{~cm}^{-1}$. When this technique was applied to mixed-alkali borate glasses, $x M_{2} \mathrm{O}-(1-x) M_{2}^{\prime} \mathrm{O}-n \mathrm{~B}_{2} \mathrm{O}_{3}$ with $M, M^{\prime}=$ different alkalis and $n=5,2$, and 1.2 , insights were obtained into the local structure of mixed-alkali glasses. ${ }^{21-25}$ Thus, while dissimilar cations were found to occupy distinctly different sites as shown in earlier studies, ${ }^{14,15}$ there was now clear evidence for one alkali influencing the local dynamics of the other in the mixed-cation glass. This effect was manifested by systematic variations in the characteristic cation-site vibration frequencies in the far infrared, indicating the strengthening of the cation-site interactions for the higher-field-strength cation (e.g., $\mathrm{Li}$ and $\mathrm{Na}$ ) and the parallel weakening of the corresponding interactions for the lower-field-strength cation (e.g., $\mathrm{Rb}$ and $\mathrm{Cs}$ ) in relation to interactions in the singlecation glasses. Thus, upon alkali mixing Li ions occupy sites corresponding to steeper potential wells, while the Cs ions are forced into sites less favorable than those in the single alkali glass. It was argued that this finding provides evidence for an effective interaction between the dissimilar alkali ions through formation of network-mediated pair configurations of unlike ions, which become effectively blocked in the mixed-cation structure. ${ }^{21-25}$ Of equal importance was also the finding that the local glass structure rearranges to fulfill the coordination needs of the dissimilar alkali-ion configurations, as manifested by a negative departure from linearity in the fraction of four-coordinated boron atoms in mixed-alkali borate glasses. ${ }^{22-25}$ The magnitude of these structural characteristics of the mixed-alkali effect was found to increase with increasing the size and field strength difference between the dissimilar alkali ions and the total alkali content, ${ }^{22,24}$ and to provide a basis for explaining the negative departure from additivity of the glass transition temperature in mixed-alkali borate glasses. ${ }^{25}$ As discussed by Ingram and co-workers ${ }^{26}$ many features of the MAE can be understood in terms of the glass network-mediated coupling between motions of dissimilar alkali ions and this includes the maximum in the activation volume for ion transport.

The need to gain more detailed information on the local structure of mixed-alkali glasses has attracted complementary experimental studies on many different mixed-cation systems. Greaves has reported changes in the XAFS spectra of mixed $\mathrm{KCsSi}_{2} \mathrm{O}_{5}$ glasses ${ }^{27}$ that indicate an improvement in the environment around $\mathrm{K}$ at the expense of the Cs environment, relative to those in the corresponding single alkali glasses. Nuclear magnetic resonance studies by Bray and coworkers on mixed-alkali borate ${ }^{28}$ and silicate ${ }^{29}$ glasses have shown that the local glass structure exhibits departures from linearity upon alkali mixing and a tendency for like-cation pairing in the latter system. On the other hand, Nuclear magnetic resonance investigation of $\mathrm{Li}-\mathrm{Na}$ metaphosphate glasses $^{30}$ has provided evidence for the presence of dissimilar alkali-ion pairs, Li-NBO-Na, which are thought to be more tightly bound relative to pairs of identical cations (NBO indicates a nonbridging oxygen atom). A dynamic angle spinning (DAS) NMR study of Na-K disilicate glasses suggested that four alkali cations are distributed in random combinations around each NBO atom, ${ }^{31}$ while Nuclear magnetic resonance studies by the spin echo double resonance (SEDOR) technique have indicated that the structural orga- nization of mixed-alkali glasses depends on the size difference between the two dissimilar cations. ${ }^{32,33}$ Thus, while the short-range order structure did not seem to change in the mixed borate glasses, unlike-cation configurations were found to be favored in $\mathrm{Li}-\mathrm{Na}$ system $^{32}$ and preference for like-cation interactions were indicated for mixed $\mathrm{Na}-\mathrm{Rb}$ borate glasses. ${ }^{33}$

Neutron scattering studies of mixed-alkali phosphate glasses by Swenson et al. ${ }^{34}$ suggested that the short-range order of the phosphate network is almost independent of composition. Also, while the environments of $\mathrm{Li}$ and $\mathrm{Rb}$ cations were shown to be distinctly different in the mixedcation glass, they were found to remain unchanged relative to environments in the corresponding single alkali glass ${ }^{34}$ as suggested by far infrared spectroscopy. ${ }^{14}$ Compared to the phosphate system, a recent neutron diffraction and reverse Monte Carlo study of Li-Rb diborate glasses concluded that the environments of alkali cations are modified significantly upon mixing. ${ }^{35}$ In particular, a compression was observed for $\mathrm{Li}$ sites with a parallel expansion of $\mathrm{Rb}$ sites in mixed-cation borate glasses.

Besides the original contributions of the dynamic structure model in the field, ${ }^{19}$ advances have been made in explaining the frequency and temperature dependence of dynamic and energetic features of the MAE by theoretical modeling, ${ }^{13,36-42}$ with most models relying on the tendency of alkali ions to occupy their own distinct coordination environments in both single and mixed-alkali glasses. Further insights into structural and dynamic aspects of mixed-alkali glasses have been achieved by molecular dynamics (MD) simulations. ${ }^{43-48}$ With the majority of MD studies dealing with silicate glasses, the emerging picture for the origin of the MAE is that of site preference exhibited by unlike-alkali ions during migration through the glass network.

Despite the numerous studies devoted to mixed-alkali glasses, there are aspects that are still not well resolved or appear to depend on the type of the studied mixed-alkali system. With reference to works cited above, of particular relevance is the question concerning the effect of alkali mixing on the short-range order of glass and on the nature of sites favored by dissimilar alkali ions. Along these lines, this work presents a MD study of mixed-alkali borate glasses of composition $0.3\left[(1-x) \mathrm{Li}_{2} \mathrm{O}-x M_{2} \mathrm{O}\right]-0.7 \mathrm{~B}_{2} \mathrm{O}_{3}$ with $M=\mathrm{Na}$ and $\mathrm{Cs}$ and $x=0,0.25,0.5,0.75$, and 1 . The choice of the Li-Na and Li-Cs mixed-cation glasses allows studying the effect of cation size difference on the above structural issues as a function of alkali mixing, $x$. A previous MD study of mixed-alkali borate glasses ${ }^{45}$ concerned only two mixed Li-Cs compositions of equal Li/Cs mixing (i.e., $x=0.5$ ) and variable $\mathrm{B}_{2} \mathrm{O}_{3}$ content $\left(60\right.$ and $\left.80 \mathrm{~mol} \% \mathrm{~B}_{2} \mathrm{O}_{3}\right)$. Also, the Li-Na glass system studied in this work was investigated previously by impedance spectroscopy in a broad temperature and frequency range. ${ }^{49}$ Besides the typical manifestation of the MAE, the shape of conductivity spectra were found to depend strongly on Li-Na mixing, and this effect was attributed to a strong reduction in the effective number of mobile ions in the mixed Li-Na glass.

\section{COMPUTATIONAL DETAILS}

Molecular dynamics calculations have been carried out for two mixed-alkali glass systems, $0.3\left[(1-x) \mathrm{Li}_{2} \mathrm{O}-x \mathrm{Na}_{2} \mathrm{O}\right]$ 
$-0.7 \mathrm{~B}_{2} \mathrm{O}_{3}$ and $0.3\left[(1-x) \mathrm{Li}_{2} \mathrm{O}-x \mathrm{Cs}_{2} \mathrm{O}\right]-0.7 \mathrm{~B}_{2} \mathrm{O}_{3}$ with $x=0$, $0.25,0.5,0.75$, and 1 in each system and the additional composition $x=0.90$ for Li-Cs. The system consisted of 1020 particles, 556 oxygen atoms, 324 boron atoms, and a total of 140 alkali cations. Experimental densities have been used for the binary glasses ${ }^{50}$ and a linear interpolation for the density of mixed-alkali glasses. ${ }^{21,22}$

MD simulations were performed in the NVT ensemble with the final temperature set equal to $T=312 \mathrm{~K}$. The particles were initially placed on an fcc lattice and heated to a temperature of $5000 \mathrm{~K}$. The cooling scheme consisted of five cooling cycles, and it was the same as in our previous calculations for the binary Li (Ref. 51) and Cs (Ref. 52) borate glasses. Each system was equilibrated at the final temperature for about $2 \mathrm{~ns}$ and properties were calculated for the next $1 \mathrm{~ns}$.

The potential form and the parameters were those employed initially by Verhoef and den Hartog 45 and, subsequently, in other studies. ${ }^{51-54}$ For the case of $\mathrm{Na}^{+}$ion, which was not considered in, 45 the ionic radius was taken equal to $1.22 \AA .{ }^{55}$ As usual, periodic boundary conditions and the Ewald summation technique were employed.

\section{RESULTS AND DISCUSSION}

\section{A. Effect of alkali mixing on the short-range order structure}

Despite the plethora of experimental and theoretical works mentioned in the introductory section, the landscape of the short-range order (SRO) structure in mixed glasses is not quite clear yet. To address this problem, we identify first the different types of borate units by examining the number of oxygen $(\mathrm{O})$ atoms coordinated to a particular boron (B) atom according to the first minimum of the $\mathrm{B}-\mathrm{O}$ radial distribution function (RDF) criterion. Following this approach, it was found that the SRO structure of all glasses studied here consists of tetrahedral and triangular boron-oxygen units with variable numbers of bridging and nonbridging oxygen atoms. In particular, two types of borate tetrahedral units were found to exist having either all $\mathrm{O}$ atoms of the bridging type, $\mathrm{B} \varnothing_{4}^{-}$, or three bridging and one nonbridging oxygen (NBO) atom, $\mathrm{B} \varnothing_{3} \mathrm{O}^{2-}(\varnothing=$ bridging oxygen atom). Similarly, neutral $\left(\mathrm{B} \varnothing_{3}\right)$ and charged borate triangular units were identified with one $\left(\mathrm{B} \varnothing_{2} \mathrm{O}^{-}\right)$or two NBOs $\left(\mathrm{B} \varnothing \mathrm{O}_{2}^{2-}\right)$. An oxygen atom is identified as NBO if it is coordinated to one boron atom within the first minimum distance of the corresponding B-O radial distribution function. It was found that tetrahedral borate units with one NBO and triangles units with two NBOs are minority species since their molar fractions are less than $2 \%$ of total borate units.

A first indication about the impact of alkali ion mixing on the SRO structure results from the examination of the B-O RDFs in the two mixed systems. The B-O RDF of the binary $0.3 \mathrm{Li}_{2} \mathrm{O}-0.7 \mathrm{~B}_{2} \mathrm{O}_{3}$ glass $(x=0)$ is compared in Fig. 1 with those of the $x=0.5$ mixed glasses $0.3\left[(1-x) \mathrm{Li}_{2} \mathrm{O}-x M_{2} \mathrm{O}\right]$ $-0.7 \mathrm{~B}_{2} \mathrm{O}_{3}$ with $M=\mathrm{Cs}$ [Fig. 1(a)] and $M=\mathrm{Na}$ [Fig. 1(b)]. It is found that mixing in the Li-Cs system has a direct influence on the SRO as manifested by the narrowing and shifting to smaller distances of the corresponding RDF. On the contrary, no significant changes upon mixing are observed for

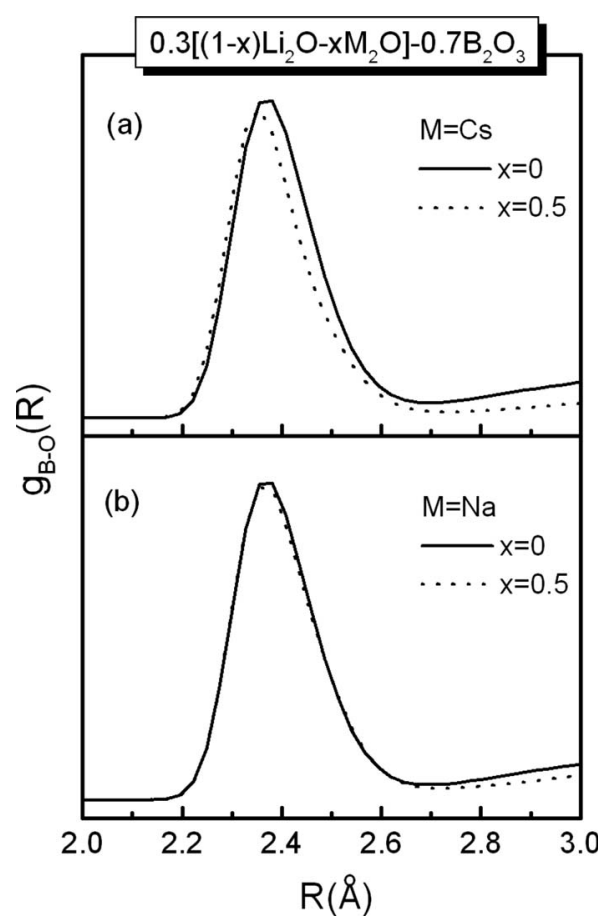

FIG. 1. Composition dependence of the first peak of the boronoxygen radial distribution function at $300 \mathrm{~K}$ for simulated glasses $0.3\left[(1-x) \mathrm{Li}_{2} \mathrm{O}-x M_{2} \mathrm{O}\right]-0.7 \mathrm{~B}_{2} \mathrm{O}_{3}$; (a) $M=\mathrm{Cs}$ and $x=0,0.5$, and (b) $M=\mathrm{Na}$ and $x=0$ and 0.5 .

the $\mathrm{Li}-\mathrm{Na}$ system. In general, the B-O RDF reflects the speciation of tetrahedral and triangular borate units in the glass matrix, with the contribution of triangular units appearing at lower B-O distances relative to that of borate tetrahedra. ${ }^{56}$ Therefore, the results suggest that the mixed Li-Cs glass is characterized by larger relative population of borate triangles compared to the binary $x=0$ glass.

To quantify the role of mixing on the SRO structure, the molar fraction of $\mathrm{B} \varnothing_{4}^{-}$units, $X_{4}$, was calculated for the simulated $\mathrm{Li}-\mathrm{Na}$ and Li-Cs glasses and is shown in Fig. 2(a) as a function of alkali mixing, $x$. A clear decrease of $X_{4}$ with $x$ is found for Li-Cs glasses, with the values of the two endmembers differing by approximately $60 \%$ and $X_{4}$ showing a negative departure from linearity with alkali mixing. The maximum deviation from linearity (approximately 23\%) is observed for maximum mixing, $x=0.5$, and this constitutes a structural manifestation of the mixed-alkali effect. However, the $X_{4}$ trend found for Li-Na glasses shows no obvious deviation from linearity considering the estimated errors. The corresponding molar fraction of $\mathrm{B} \varnothing_{2} \mathrm{O}^{-}$units, $X_{2}$, is shown in Fig. 2(b). As expected for reasons of charge neutrality, $X_{2}$ follows a positive deviation from linearity for Li-Cs glasses but it exhibits no systematic trend in Li-Na glasses. Therefore, under fixed total alkali content the SRO borate structure remains practically unaffected in the Li-Na system contrary to Li-Cs glasses where the largest differences exist in size and field strength between the dissimilar alkali ions.

A detailed discussion of the dependence of the SRO structure on the alkali cation type was given in our previous work $^{52}$ for single alkali borate glasses. The present MD results on mixed-alkali borate glasses are in good agreement 


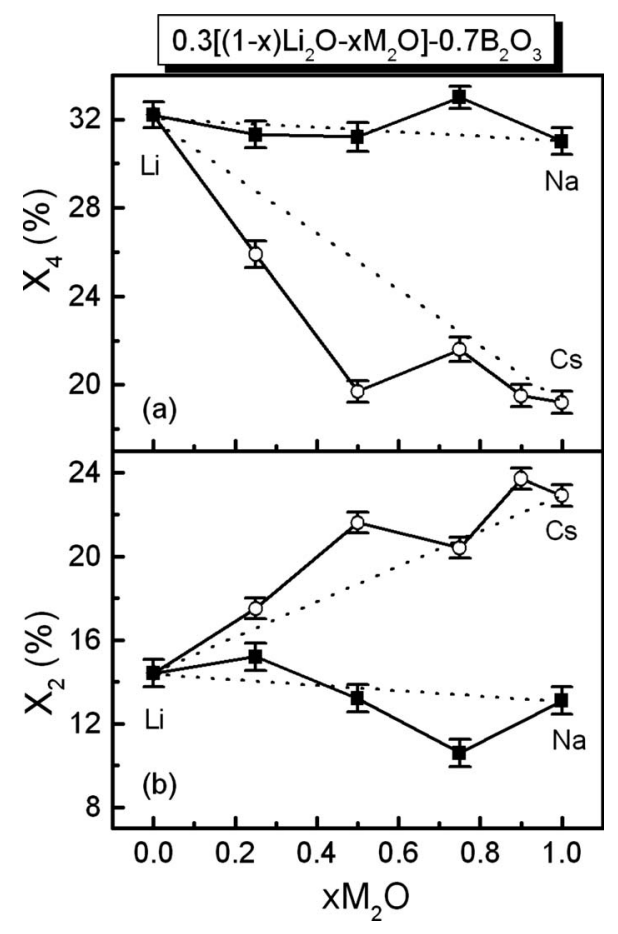

FIG. 2. Molar fractions at $T=300 \mathrm{~K}$ of short-range order structural units in simulated glasses $0.3\left[(1-x) \mathrm{Li}_{2} \mathrm{O}-x M_{2} \mathrm{O}\right]-0.7 \mathrm{~B}_{2} \mathrm{O}_{3}$ $(M=\mathrm{Cs}$ and $\mathrm{Na})$ as a function of alkali mixing, $x$; (a) $\mathrm{B} \varnothing_{4}^{-}$units, $X_{4}$, and (b) $\mathrm{B}_{2} \mathrm{O}^{-}$units, $X_{2}$.

with earlier findings by infrared ${ }^{22-25}$ and $\mathrm{NMR}^{28}$ spectroscopy. Both experimental techniques have shown that the relative population of borate tetrahedral units in mixed-alkali diborate glasses is less than that expected from a linear structural interpolation between the two end-member glasses. It was also found that the magnitude of this deviation reduces as the difference between the two dissimilar alkalis becomes smaller.

\section{B. Alkali-ion environments in mixed-alkali glasses}

The SRO borate units provide the oxygen atoms constituting the coordination environments of the alkali metal cations. Considering the effect of alkali mixing on the SRO structures discussed in the preceding section the question that arises now is whether the alkali ions in mixed glasses retain the coordination environments they have in the corresponding single alkali glasses. It was found in previous MD studies of single alkali borate glasses that alkali ions occupy two types of distinct sites. ${ }^{51-53}$ The first type of site consists only of bridging oxygen atoms that are provided by neutral borate triangles $\left(\mathrm{B} \varnothing_{3}\right)$ and $\mathrm{B} \varnothing_{4}^{-}$tetrahedra, and they were labeled $b$-type sites. The second type of sites, denoted nbtype, is formed by both bridging oxygen atoms (of $\mathrm{B} \varnothing_{3}$ units) and NBO atoms of charged borate triangles $\left(\mathrm{B}_{2} \mathrm{O}^{-}\right)$. Another characteristic of these types of site is that $b$-type sites can be regarded as rather isolated sites, whereas nb-type sites tend to aggregate and, thus, they are multiply occupied by alkali metal ions. ${ }^{57}$

Figures 3(a) and 3(b) present the composition dependence of the $\mathrm{Li}-\mathrm{O}$ and $\mathrm{Cs}-\mathrm{O}$ radial distribution functions, respec-

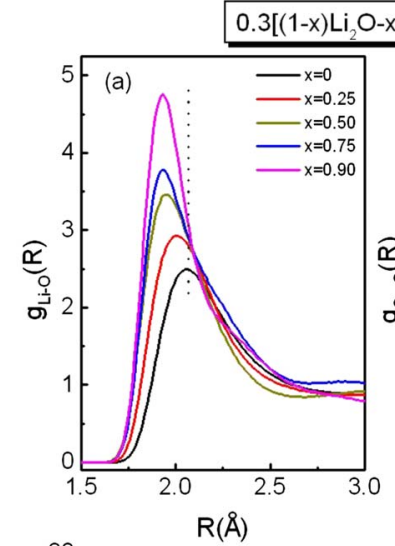

$0.3\left[(1-\mathrm{x}) \mathrm{Li}_{2} \mathrm{O}-\mathrm{x} \mathrm{Cs}_{2} \mathrm{O}\right]-0.7 \mathrm{~B}_{2} \mathrm{O}_{3}$
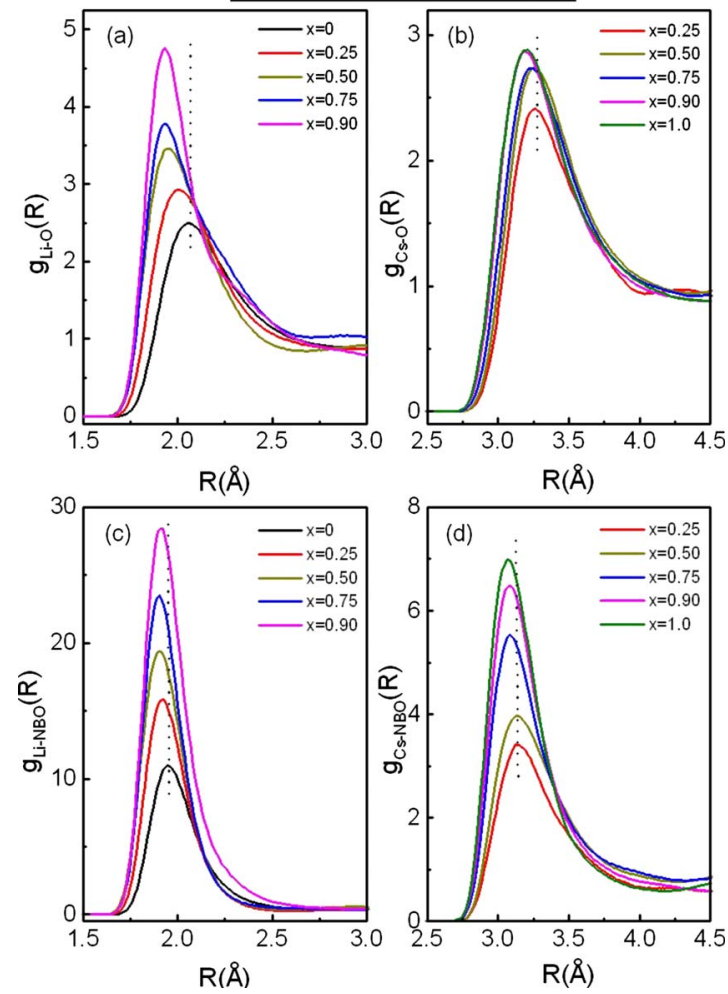

FIG. 3. (Color online) Effect of alkali mixing, $x$, on the first peak of the alkali metal ion-oxygen radial distribution functions at $300 \mathrm{~K}$ for simulated glasses $0.3\left[(1-x) \mathrm{Li}_{2} \mathrm{O}-x \mathrm{Cs}_{2} \mathrm{O}\right]-0.7 \mathrm{~B}_{2} \mathrm{O}_{3}$; (a) $\mathrm{Li}-\mathrm{O}$, (b) Cs-O, (c) Li-NBO, and (d) Cs-NBO RDFs. Bottom-up: $x=0,0.25,0.50,0.75$, and 0.90 in frames (a) and (c). Bottom-up: $x=0.25,0.50,0.75,0.90$, and 1 in frames (b) and (d).

tively, in the region of the first coordination shell. The peak of the Li-O RDFs exhibits a systematic shift to smaller distances with alkali mixing only up to $x=0.5$. The corresponding Cs-O peak shows the opposite trend by shifting to higher distances as the $\mathrm{Cs}$ ions are progressively replaced by $\mathrm{Li}$ ions. The fact that the observed shifts are not drastic, i.e., about $0.13 \AA$ for $\mathrm{Li}-\mathrm{O}$ and $0.06 \AA$ for Cs-O, implies that each alkali ion retains its own characteristic environment which is similar to that formed in the corresponding single alkali glass. Besides the decreasing Li-O distance, the corresponding first peak becomes sharper under alkali mixing as observed in Fig. 3(a). These findings imply enhanced Li-O interactions and better defined coordination environments for $\mathrm{Li}$ ions in mixed glasses. The corresponding trends of the Cs-O pair distribution function in Fig. 3(b) suggest the weakening of the Cs-O interactions upon mixing, with no pronounced change in the width of the $\mathrm{Cs}-\mathrm{O}$ peak. The calculated coordination numbers of $\mathrm{Li}$ and $\mathrm{Cs}$ ions with oxygen atoms are summarized in Table I. Clear nonmonotonic trends emerge with the coordination number of $\mathrm{Li}$ acquiring a minimum value at equal mixing $(x=0.5)$, while that of $\mathrm{Cs}$ passes through a maximum. This behavior may result from a number of factors as discussed below.

The observed changes in alkali-oxygen environments can be induced through polarization effects if the dissimilar Li and $\mathrm{Cs}$ ions occupy neighboring network sites and share oxy- 
TABLE I. Coordination numbers of metal ions with oxygen, $M(\mathrm{O})$, in mixed $\mathrm{Li}-\mathrm{Cs}$ and $\mathrm{Li}-\mathrm{Na}$ borated glasses $0.3[(1$ $\left.-x) \mathrm{Li}_{2} \mathrm{O}-x M_{2} \mathrm{O}\right]-0.7 \mathrm{~B}_{2} \mathrm{O}_{3}, M=\mathrm{Cs}$ and $\mathrm{Na}$, as a function of $M_{2} \mathrm{O}$ mole fraction.

\begin{tabular}{lcclll}
\hline \hline \multirow{2}{*nnnn}{$x$} & \multicolumn{2}{c}{ Li-Cs glasses } & & \multicolumn{2}{c}{ Li-Na glasses } \\
\cline { 2 - 3 } \cline { 5 - 6 } \cline { 5 - 6 } 0 & $\mathrm{Li}(\mathrm{O})$ & $\mathrm{Cs}(\mathrm{O})$ & & $\mathrm{Li}(\mathrm{O})$ & $\mathrm{Na}(\mathrm{O})$ \\
0.25 & 4.62 & & & 4.62 & \\
0.5 & 4.07 & 11.64 & & 4.48 & 6.86 \\
0.75 & 3.70 & 12.90 & & 4.37 & 7.03 \\
0.90 & 3.94 & 10.87 & & 4.81 & 6.97 \\
1 & 4.04 & 10.67 & & \\
\hline \hline
\end{tabular}

gen atoms in their first coordination spheres. As it will be shown in the following section, an NBO atom has enhanced probability of being shared by dissimilar cations than by similar ones and this constitutes a key feature for the origin of the MAE. Such a mixing of dissimilar alkali cations would favor the coordination needs of $\mathrm{Li}$ ions which, having much higher-field strength than Cs ions, would force the latter ions to occupy less favorable sites. As found above, this process is facilitated in mixed-alkali glasses by transformation of tetrahedral borate units into NBO-containing triangular units, which leads to more open space in the glass network and enables Li cations to approach closer to oxygen atoms for compositions up to $x=0.5$. This leads to smaller $\mathrm{Li}(\mathrm{O})$ coordination numbers as shown in Table I. For higher mixing ratios, and despite the fact that the first shell in the corresponding Li-O RDF becomes sharper, a parallel broadening at higher distances is observed and reflects the destabilization of the local $\mathrm{Li}$ environment due to the increasing presence of $\mathrm{Cs}$ ions. This, in turn, results in increasing $\mathrm{Li}(\mathrm{O})$ coordination number. At the same time, the opposite behavior is observed for $\mathrm{Cs}$ ions, i.e., a maximum of $\mathrm{Cs}(\mathrm{O})$ coordination at $x=0.5$.

Considering the important role of nonbridging oxygen atoms in ion transport properties, ${ }^{51-53,56}$ we examine further the behavior of alkali ions in the vicinity of NBOs. To this aim, Figs. 3(c) and 3(d) demonstrate the effect of alkali mixing on the Li-NBO and Cs-NBO RDFs in the region of the first coordination shell. Comparison with Figs. 3(a) and 3(b) shows that for both $\mathrm{Li}$ and $\mathrm{Cs}$ ions the $M$-NBO distance is smaller than the corresponding $M-\mathrm{O}$ distance, but the trends with alkali mixing remain the same as before.

The effect of alkali mixing on the $\mathrm{Li}-\mathrm{O}$ and $\mathrm{Na}-\mathrm{O}$ radial distribution functions is depicted in Figs. 4(a) and 4(b) for glasses in the Li-Na system. It is found in this case that both the position and the width of the first peak remain practically unaffected by alkali mixing. This behavior of the average $\mathrm{Li}-\mathrm{O}$ and $\mathrm{Na}-\mathrm{O}$ coordination environments is consistent with the absence of profound SRO structural variations [see Figs. 1(b), 2(a), and 2(b)], and these results can be understood in terms of the smaller difference in size and cationic field strength between $\mathrm{Li}$ and $\mathrm{Na}$ ions relative to the $\mathrm{Li}-\mathrm{Cs}$ pair. It is noted, however, that the absence of SRO structural changes does not exclude the possibility of $\mathrm{Li}$ and $\mathrm{Na}$ ions
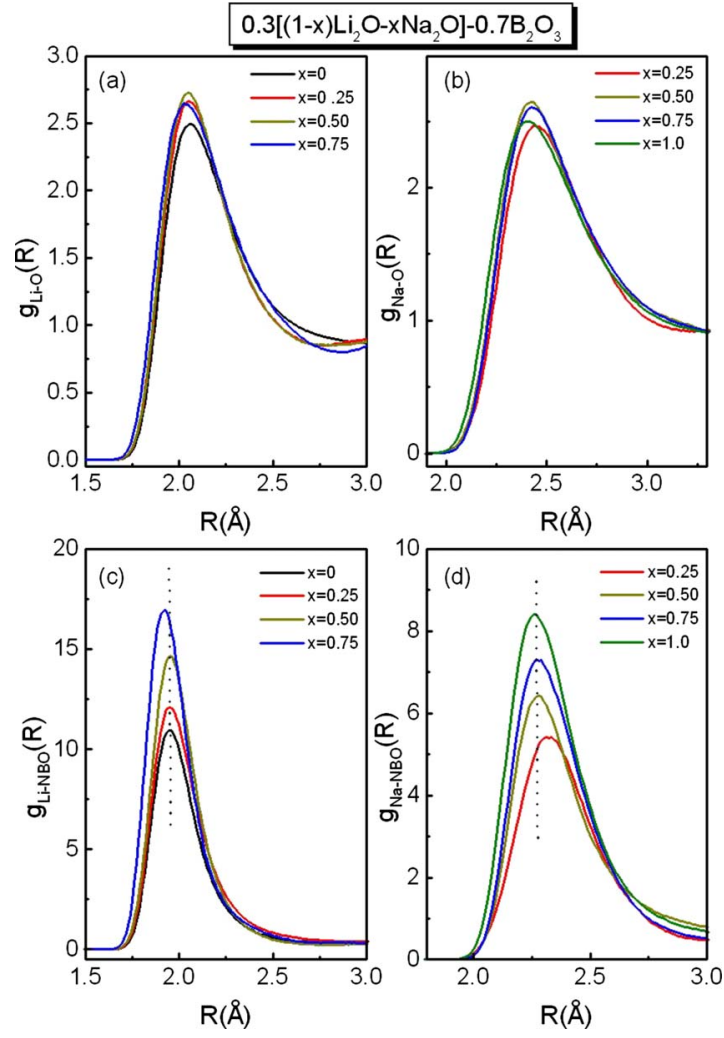

FIG. 4. (Color online) Effect of alkali mixing, $x$, on the first peak of the alkali metal ion-oxygen radial distribution functions at $300 \mathrm{~K}$ for simulated glasses $0.3\left[(1-x) \mathrm{Li}_{2} \mathrm{O}-x \mathrm{Na}_{2} \mathrm{O}\right]-0.7 \mathrm{~B}_{2} \mathrm{O}_{3}$; (a) Li-O, (b) Na-O, (c)Li-NBO, and (d) Na-NBO RDFs. Bottom-up: $x=0,0.25,0.50$, and 0.75 in frames (a) and (c). Bottom-up: $x$ $=0.25,0.50,0.75$, and 1 in frames $(b)$ and $(d)$.

occupying neighboring sites in mixed Li-Na glasses. This notion is supported by Figs. 4(c) and 4(d) which show that both Li-NBO and Na-NBO RDFs are affected by alkali mixing and exhibit trends similar to those found for the $\mathrm{Li}-\mathrm{Cs}$ system. The same holds for the $\mathrm{Li}(\mathrm{O})$ and $\mathrm{Na}(\mathrm{O})$ coordination numbers reported in Table I, although the variations are less pronounced in the Li-Na system due to the smaller difference in field strength of the two competing cations.

As shown in Fig. 2, there is a preference in Li-Cs glasses for creation of NBO-containing triangular units upon mixing at the expense of borate tetrahedra with bridging oxygen atoms. In this respect, it is worth examining whether both $\mathrm{Li}$ and $\mathrm{Cs}$ ions sense an increased number of NBOs in mixed glasses compared to their environments in the single alkali glasses. As in our previous works, we label the alkali ions as nb-type ions $\left(M^{\mathrm{nb}}\right)$ if they remain in the vicinity of an NBO atom for more than $75 \%$ of the total simulation time..$^{51-53}$ The relative populations of $\mathrm{Li}^{\mathrm{nb}}$ and $\mathrm{Cs}^{\mathrm{nb}}$ ions are depicted in Fig. 5(a) as a function of $\mathrm{Li} / \mathrm{Cs}$ mixing. It is clear that the percentage of $\mathrm{Li}^{\mathrm{nb}}$ ions increases considerably with mixing and approaches $100 \%$ at $x=0.90$ where $\mathrm{Li}$ ions are the minority species, whereas the $\mathrm{Cs}^{\mathrm{nb}}$ relative population follows the opposite trend. These trends can be understood in terms of the increased population of NBO atoms in the glass network upon alkali mixing, Fig. 2(b).

Despite the opposite trends of $\mathrm{Li}^{\mathrm{nb}}$ and $\mathrm{Cs}^{\mathrm{nb}}$ populations in the mixed glasses under investigation, it is found that both 


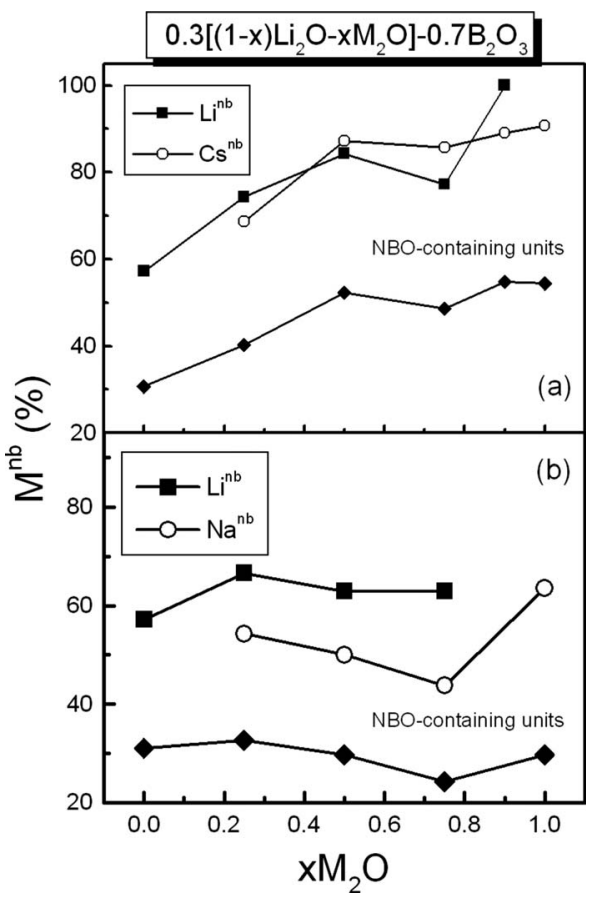

FIG. 5. Percentage of metal ions in the vicinity of NBO atoms, $M^{\mathrm{nb}}$, for simulated glasses $0.3\left[(1-x) \mathrm{Li}_{2} \mathrm{O}-x M_{2} \mathrm{O}\right]-0.7 \mathrm{~B}_{2} \mathrm{O}_{3}$ as a function of $x$ at $T=300 \mathrm{~K}$; (a) $M=\mathrm{Cs}$, and (b) $M=\mathrm{Na}$. The corresponding percentages of borate units with $\mathrm{NBO}$ atoms are also presented.

populations are by far greater than the relative population of the NBO-containing borate units as seen in Fig. 5(a). For charge neutrality reasons, each alkali cation would in principle charge-balance a single negative charge either on a triangular borate unit or on a borate tetrahedron with all oxygen atoms being bridging. If all alkali metal cations were distributed proportionally between the charged triangular and tetrahedral borate units, then one would expect a close agreement between the sum of $\mathrm{Li}^{\mathrm{nb}}$ and $\mathrm{Cs}^{\mathrm{nb}}$ populations and that of the NBO-containing borate units. However, this is not the case. For instance, at $x=0$ (i.e., for the binary Li glass) the proportion of NBO-containing units relative to the total number of the charged borate units is $30.7 \%$ while $\mathrm{Li}^{\mathrm{nb}}$ ions account for $57.2 \%$ of their total content. Also, at $x=0.25$ the NBO-containing units are $40.3 \%$ of the total number of charged units while the populations of $\mathrm{Li}^{\mathrm{nb}}$ and $\mathrm{Cs}^{\mathrm{nb}}$ ions are $74.3 \%$ and $68.6 \%$, respectively, of their total content. The same trend is followed by all remaining glass compositions and, as it will be shown later, this finding can be explained by considering the number of alkali ions that are found in the vicinity of NBO atoms which shows that each NBO oxygen "sees" more than one alkali ions.

Figure 5(b) shows the percentages of the nb-type alkali cations and of the NBO-containing units for Li-Na mixedalkali glasses. While the trends are less profound than those exhibited by Li-Cs glasses in Fig. 5(a), there is again evidence for a preference of alkali cations to occupy nb-type sites. Therefore, in mixed-alkali borate glasses there is an enhanced tendency relative to that in single alkali glasses for alkali cations to reside in nb-type sites rather than into $b$-type sites.

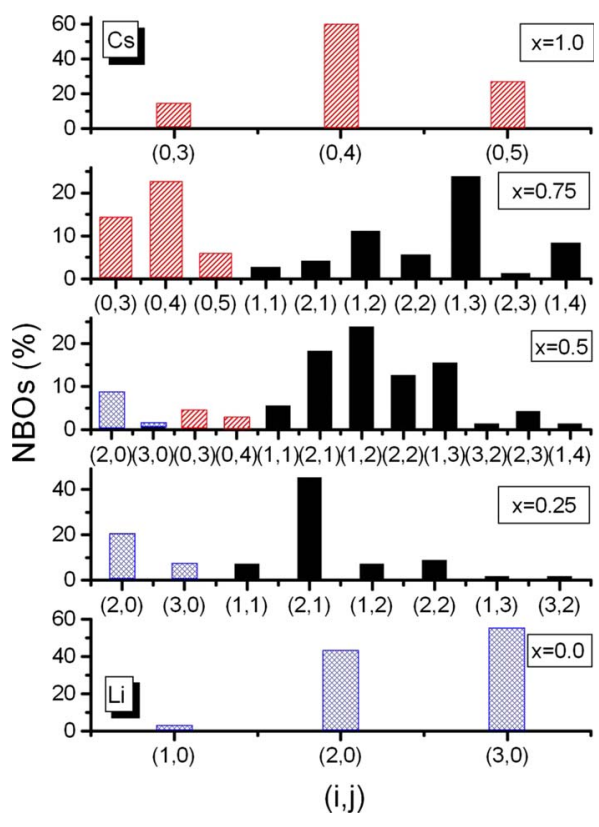

FIG. 6. (Color online) Percentage of NBO atoms that sense in their vicinity $(i, j)$ cation configurations, where $i$ and $j$ are the numbers of $\mathrm{Li}$ and $\mathrm{Cs}$ ions, respectively, as a function of alkali mixing $(x)$ for mixed glasses $0.3\left[(1-x) \mathrm{Li}_{2} \mathrm{O}-x \mathrm{Cs}_{2} \mathrm{O}\right]-0.7 \mathrm{~B}_{2} \mathrm{O}_{3}$ simulated at $T=300 \mathrm{~K}$. Like-cation configurations are denoted by crossed bars for $\mathrm{Li}$ ions and hatched bars for $\mathrm{Cs}$ ions. Black bars indicate unlikeion configurations $(i \mathrm{Li}, j \mathrm{Cs})$ close to NBOs. For details see text.

\section{Environments of nonbridging oxygen atoms in mixed-alkali glasses}

As presented in the previous paragraphs, the NBOs act as attractive centers for alkali cations in mixed glasses. Therefore, a careful examination of NBO environments can provide an effective means for probing the existence of unlikeor like-cation clustering in mixed-cation glasses. The picture emerging from the point of view of NBO environments may provide useful information for understanding the roots of the mixed-alkali effect.

Figure 6 shows the percentage of NBO atoms in Li-Cs glasses that sense a certain cation configuration within the first minimum of the NBO-cation RDF. Each frame of Fig. 6 corresponds to a particular alkali mixing; the one at the bottom to $x=0($ all $\mathrm{Li})$, the other at the top to $x=1$ (all Cs) and intermediate frames reflect the situation in mixed-alkali glasses. Each bar is labeled by $(i, j)$ where $i$ and $j$ give the number of $\mathrm{Li}$ and $\mathrm{Cs}$ ions, respectively, in close proximity to an NBO atom. Thus, the bars $(i, 0)$ or $(0, j)$ denote, respectively, the percentage of $\mathrm{NBO}$ atoms "seeing" $i \mathrm{Li}$ or $j \mathrm{Cs}$ ions only. These configurations constitute the like-cation clustering in single alkali glasses, while $(i, j)$ configurations-with $i$ and $j$ different than zero-indicate unlike-cation clustering in mixed-alkali glasses.

Starting with the two end-member glasses, we find that the most probable cation configurations close to an NBO atom are those consisting of $3 \mathrm{Li}$ and $4 \mathrm{Cs}$ for $x=0$ and $x=1$, respectively. This trend is consistent with the results shown in Fig. 5 where the proportion of NBO-containing units was found to be considerable smaller than the percentage of $\mathrm{Li}^{\mathrm{nb}}$ 


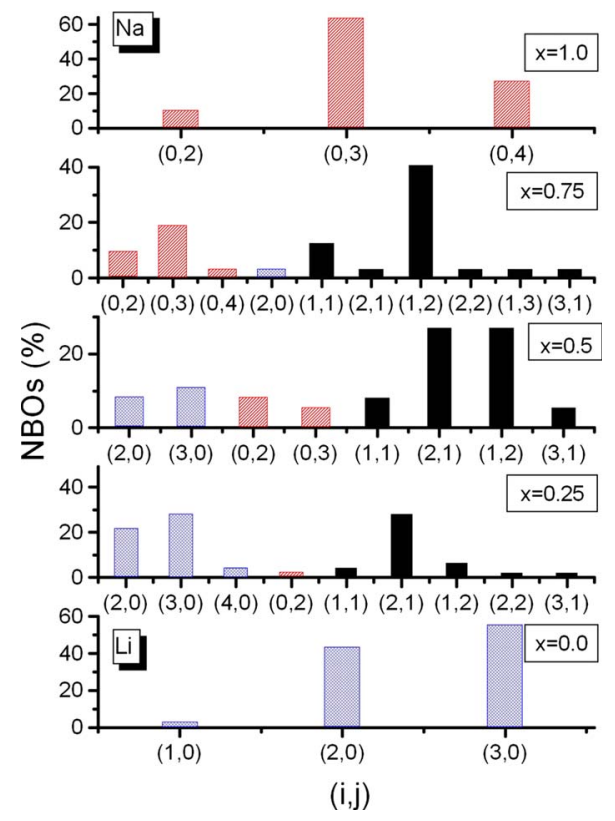

FIG. 7. (Color online) Percentage of NBO atoms that sense in their vicinity $(i, j)$ cation configurations, where $i$ and $j$ are the numbers of $\mathrm{Li}$ and $\mathrm{Na}$ ions, respectively, as a function of alkali mixing $(x)$ for mixed glasses $0.3\left[(1-x) \mathrm{Li}_{2} \mathrm{O}-x \mathrm{Na}_{2} \mathrm{O}\right]-0.7 \mathrm{~B}_{2} \mathrm{O}_{3}$ simulated at $T=300 \mathrm{~K}$. Like-cation configurations are denoted by crossed bars for $\mathrm{Li}$ ions and hatched for $\mathrm{Na}$ ions. Black bars indicate unlikeion configurations $(i \mathrm{Li}, j \mathrm{Na})$ close to NBOs. For details see text.

and $\mathrm{Cs}^{\mathrm{nb}}$ ions. When $\mathrm{Cs}$ ions are introduced into the Li glass at the mixing ratio $x=0.25$ the $(2,1)$ becomes by far the dominant configuration, i.e., consisting of $2 \mathrm{Li}$ and $1 \mathrm{Cs}$ ions, as compared to the $3 \mathrm{Li} \mathrm{most} \mathrm{probable} \mathrm{configuration} \mathrm{at} x=0$. At equal mixing, $x=0.50$, the $(2,1)$ and $(1,2)$ are the dominant configurations and at $x=0.75$ the configurations $(1,3)$ and $(0,4)$ prevail. Thus, the resulting picture in $\mathrm{Li}-\mathrm{Cs}$ glasses is that as Cs becomes the majority species there is both a gradual replacement of $\mathrm{Li}$ by $\mathrm{Cs}$ ions in the original $(i, 0)$ configurations and an increase from 3 to 4 of alkali ions around an NBO.

The statistics of $[i \mathrm{Li}, j \mathrm{Na}]$ configurations around $\mathrm{NBO}$ atoms in Li-Na glasses are reported in Fig. 7. As the Na content increases the dominant configurations $(3,0)$ and $(2,0)$ at $x=0$ are replaced at $x=0.25$ by the $(2,1)$ configuration, at $x$ $=0.5$ by $(2,1)$ and $(1,2)$ and by $(1,2)$ and $(0,3)$ at $x=0.75$. Finally, the ion statistics around NBOs in the Na single alkali glass are dominated by configuration $(0,3)$.

The pattern of formation of the most favorable $[i \mathrm{Li}, j M]$ configurations $(M=\mathrm{Na}$ and $\mathrm{Cs})$ is summarized in Table II for the glasses investigated here. A common picture has emerged and this concerns the presence of both like- and unlike-cation clustering configurations in mixed-alkali glasses, with the latter ones prevailing upon alkali mixing. It is noted also that in both systems the alkali cations are found mostly in triads around NBO atoms, except for Li-Cs glasses with Cs contents higher than $x=0.5$ where $[\mathrm{Li}, \mathrm{Cs}]$ ions are found mostly in quadruplets. Regarding the present results we note that the NMR study of Florian and co-workers ${ }^{31}$ on mixed Na-K disilicate glasses has also suggested a random mixing of dissimilar alkalis on four different sites around nonbridging
TABLE II. Dominant configurations of alkali ion clustering around a nonbridging oxygen atom in mixed $\mathrm{Li}-\mathrm{Na}$ and $\mathrm{Li}-\mathrm{Cs}$ borated glasses $0.3\left[(1-x) \mathrm{Li}_{2} \mathrm{O}-x M_{2} \mathrm{O}\right]-0.7 \mathrm{~B}_{2} \mathrm{O}_{3}, M=\mathrm{Na}$ and $\mathrm{Cs}$, as a function of $\mathrm{M}_{2} \mathrm{O}$ mole fraction.

\begin{tabular}{lcc}
\hline \hline \multicolumn{1}{c}{$x$} & Li-Na glasses & Li-Cs glasses \\
\hline 0 & {$[3 \mathrm{Li}]$} & {$[3 \mathrm{Li}]$} \\
0.25 & {$[3 \mathrm{Li}]$ and $[2 \mathrm{Li}, 1 \mathrm{Na}]$} & {$[2 \mathrm{Li}, 1 \mathrm{Cs}]$} \\
0.5 & {$[2 \mathrm{Li}, 1 \mathrm{Na}]$ and $[1 \mathrm{Li}, 2 \mathrm{Na}]$} & {$[2 \mathrm{Li}, 1 \mathrm{Cs}]$ and $[1 \mathrm{Li}, 2 \mathrm{Cs}]$} \\
0.75 & {$[1 \mathrm{Li}, 2 \mathrm{Na}]$} & {$[1 \mathrm{Li}, 3 \mathrm{Cs}]$ and $[4 \mathrm{Cs}]$} \\
1 & {$[3 \mathrm{Na}]$} & {$[4 \mathrm{Cs}]$} \\
\hline \hline
\end{tabular}

oxygen atoms. Other NMR studies on mixed-alkali borate glasses have indicated that unlike-cation configurations are favored in the $\mathrm{Li}-\mathrm{Na}$ system, ${ }^{32}$ but like-cation configurations were found to be preferred in mixed $\mathrm{Na}-\mathrm{Rb}$ borate glasses. ${ }^{33}$

The results presented in Figs. 6 and 7, in terms of configurations of both like and unlike pairs of cations around NBO atoms, are now depicted in Fig. 8 in terms of the percentage of NBOs that see like-cation configurations. The striking feature of this figure is that the population of NBOs coordinated to like-cation configurations becomes minimum at maximum mixing $(x=0.5)$ where it reaches $17 \%$ and $32 \%$ of the total NBO content in Li-Cs and Li-Na glasses, respectively. This finding demonstrates a structural manifestation of MAE and highlights the importance of dissimilar cation pairing around NBOs for the interpretation of the MAE. We consider next the implications of dissimilar cation pairing on ion transport in mixed-alkali glasses.

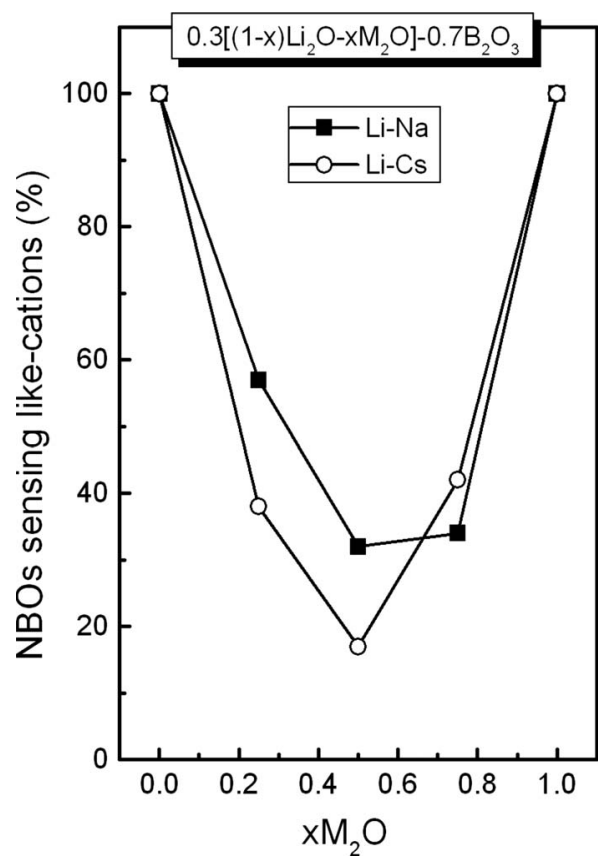

FIG. 8. Percentage of NBO atoms that sense in their vicinity like-alkali ion configurations in simulated glasses $0.3[(1$ $\left.-x) \mathrm{Li}_{2} \mathrm{O}-x M_{2} \mathrm{O}\right]-0.7 \mathrm{~B}_{2} \mathrm{O}_{3}$ glasses $(M=\mathrm{Cs}$ and $\mathrm{Na})$ as a function of alkali mixing, $x$, at $T=300 \mathrm{~K}$. 
As discussed in earlier MD studies ${ }^{51-53}$ the ion transport mechanism in single alkali borate glasses is primarily NBOassisted. Although the interactions of alkali ions with NBO atoms are stronger compared to those with bridging oxygen atoms of charged $\mathrm{B} \varnothing_{4}^{-}$tetrahedral units, the NBO-associated alkali ions exhibit enhanced mobility. This apparent paradox is resolved when we consider the clear tendency of NBO atoms to agglomerate into clusters, this effect having a similar consequence for the alkali ions in the vicinity of NBOs. In addition, the calculated cluster-size distribution curves were found to obey closely the predictions of percolation theory, thus indicating the percolative nature of ionic conductivity in alkali borate glasses. ${ }^{56}$

In mixed Li-Cs glasses the NBO population was found to increase further with alkali mixing and to follow a positive departure from linearity, see Fig. 5(a). Thus, according to the results for single alkali borate glasses, ${ }^{51-53,56}$ one might expect that this would lead to enhanced diffusivity of alkali ions in mixed Li-Cs glasses. However, well-known experimental evidence shows vast reductions in diffusion coefficients of both alkali ions and in the ionic conductivity upon alkali mixing. ${ }^{5}$ This apparent controversy can be removed by recalling the following: (i) alkali ions form their own distinct sites that retain at large their character in mixed-alkali glasses, ${ }^{14,15,21-25,27}$ (ii) because of size mismatch, an alkali ion cannot jump into a site occupied previously by a dissimilar ion, ${ }^{19}$ and (iii) there is a tendency for unlike-cations to cluster around NBOs in mixed-alkali glasses. The combination of these structural/energetic characteristics leads to effective blocking ${ }^{19}$ of the pathways for long-range diffusive motion of each type of alkali ions, and, thus, to the appearance of the MAE. The way that dissimilar cations in neighboring sites block the diffusion pathways in mixed-cation glasses has been described recently in terms of a leaderfollower microscopic model. ${ }^{26}$ The mechanism involves the loss of synergy in hopping events of individual cations due to an additional activation volume that a cation of one type requires in order to occupy a freshly vacated site of a dissimilar cation. Therefore, we suggest that clustering of dissimilar cations around NBOs constitutes a key feature responsible for the appearance of the mixed-alkali effect. For the mixed-alkali glasses investigated in this work the content of NBOs associated with like-cation configurations was found to exhibit well-defined minimum at $x=0.5$. Naturally, such a result implies maximum interception of the effective ion pathways at maximum mixing and, thus, the appearance of minimum in the value of ionic conductivity. It would have been more appropriate to calculate ionic diffusion coefficients in order to make direct connection between structural and dynamic aspects of the mixed-alkali effect. However, the present calculations were conducted only at room temperature, and at this temperature the resultant diffusion coefficients are very small and practically not reliable. It is noted that tracer diffusivities in mixed-cation glasses are determined experimentally at temperatures usually above 500 $\mathrm{K} .{ }^{58,59}$ Therefore, under the present conditions the observation of long range diffusion would require the extension of simulations for very long times.

The present findings that the bottleneck in ionic mobility of mixed-alkali glasses can be traced to the tendency of dis-

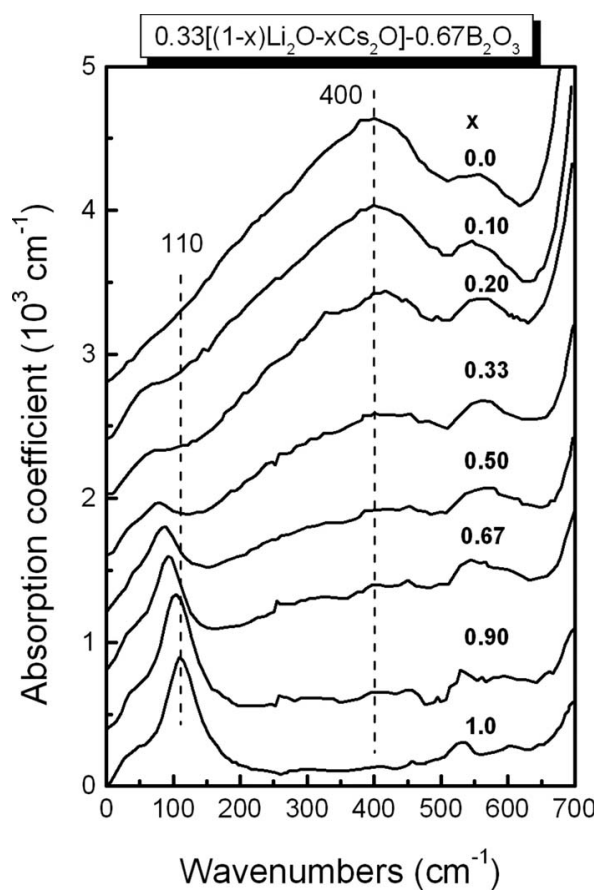

FIG. 9. Experimental far infrared absorption spectra of mixedalkali glasses $0.33\left[(1-x) \mathrm{Li}_{2} \mathrm{O}-x \mathrm{Cs}_{2} \mathrm{O}\right]-0.67 \mathrm{~B}_{2} \mathrm{O}_{3}$ as a function of alkali mixing, $x$.

similar cations to cluster around NBOs are in line with earlier propositions for the predominance of network-mediated pair configurations of dissimilar alkali ions. ${ }^{8-13,24-27,42}$

\section{Metal ion-oxide site vibrations: Experimental and calculated far infrared spectra}

It was shown above that the alkali metal-oxygen $(M-\mathrm{O})$ RDFs and the environments of NBOs vary systematically with alkali mixing. Since these results suggest changes in the $M-\mathrm{O}$ interactions, we examine here their implications on the cation-oxygen site vibrations, $\nu(M-\mathrm{O})$, focusing on the $\mathrm{Li}-\mathrm{Cs}$ system where alkali mixing has more profound effects on glass structure. Far infrared spectra reproduced from experimental data in Ref. 23 are presented in Fig. 9 for Li-Cs glass compositions $0.33\left[(1-x) \mathrm{Li}_{2} \mathrm{O}-x \mathrm{Cs}_{2} \mathrm{O}\right]-0.67 \mathrm{~B}_{2} \mathrm{O}_{3}$, which are very close to those simulated in the present study. The far infrared spectra of the binary glasses $0.33 \mathrm{Li}_{2} \mathrm{O}-0.67 \mathrm{~B}_{2} \mathrm{O}_{3}$ $(x=0)$ and $0.33 \mathrm{Cs}_{2} \mathrm{O}-0.67 \mathrm{~B}_{2} \mathrm{O}_{3}(x=1)$ are dominated by absorption bands peaking at approximately 400 and $110 \mathrm{~cm}^{-1}$, respectively. These bands originate from the rattling motions of $\mathrm{Li}$ and $\mathrm{Cs}$ ions in local sites provided by oxygen atoms ${ }^{60-62}$ while further studies have shown that the asymmetry of the far infrared profiles can be accounted for by the presence of two component bands. For $x=1$ the higherfrequency component at $110 \mathrm{~cm}^{-1}$ ( $H$ band) is accompanied by a lower-frequency shoulder at approximately $50 \mathrm{~cm}^{-1}(L$ band), while for $x=0$, the $H$ and $L$ bands were deconvoluted at 420 and $255 \mathrm{~cm}^{-1}$, respectively. ${ }^{60-62}$ The presence of $H$ and $L$ bands was taken to indicate the existence of at least two different distributions of cation-hosting sites in binary alkali borate glasses, as confirmed later by molecular dynam- 
ics studies on Li- and Cs-borate glasses. ${ }^{51-53}$ It was further shown that the lower-frequency $L$ band originates mostly from vibrations of alkali cations in sites consisting only of bridging oxygen atoms of neutral borate triangles $\left(\mathrm{B} \varnothing_{3}\right)$ and charged $\mathrm{B} \varnothing_{4}^{-}$tetrahedra ( $b$-type sites). Also, when NBO atoms of charged borate triangles $\mathrm{B}{ }_{2} \mathrm{O}^{-}$participate in site formation together with of $\mathrm{B} \varnothing_{3}$ units (nb-type sites) the metal ion-oxygen site vibration contributes to the higherfrequency component ( $H$ band). From the point of view of cation-occupancy around oxide anionic sites it was suggested that $b$-type sites can be regarded also as singly occupied sites, whereas nb-type sites correspond to multiply occupied oxide sites. ${ }^{57}$ This aspect of the nature of anionic sites was based on findings from simulations that alkali ions coordinated to bridging oxygen atoms of borate tetrahedra are rather isolated, while cations close to NBOs tend to aggregate and to form eventually percolating clusters when the alkali content exceeds a certain threshold value. ${ }^{51-53,56}$

Figure 9 shows that the Cs ion-oxide site vibration band at $110 \mathrm{~cm}^{-1}$ ( $H$ band) loses intensity and shifts to lower frequencies as $\mathrm{Cs}$ ions are replaced progressively by $\mathrm{Li}$ ions. While the intensity variation is consistent with the decreasing content of $\mathrm{Cs}$ ions, the shift of $\nu(\mathrm{Cs}-\mathrm{O})$ to lower frequencies manifests directly a decreasing strength of the Cs-O interactions upon increasing $\mathrm{Li}$ ion content. This infrared result is fully consistent with the trend of the $\mathrm{Cs}-\mathrm{O}$ pair distribution function which shows also a weakening of the Cs-O interactions upon mixing with $\mathrm{Li}$ ions [Fig. 3(b)], and, thus, both demonstrate aspects of the influence of dissimilar cations on each other.

To search further for the effect of Li ions on the Cs-oxide sites, especially when $\mathrm{Cs}$ ions are the minority species, we present in Fig. 10 difference far infrared spectra for $x=0.05$, 0.10 , and 0.20 . These spectra were obtained by subtracting the far infrared profile of the binary $0.33 \mathrm{Li}_{2} \mathrm{O}-0.67 \mathrm{~B}_{2} \mathrm{O}_{3}$ glass, spectrum $x=0.0$ in Fig. 9, from the corresponding spectra of the mixed Li-Cs glasses $0.33\left[(1-x) \mathrm{Li}_{2} \mathrm{O}-x \mathrm{Cs}_{2} \mathrm{O}\right]$ $-0.67 \mathrm{~B}_{2} \mathrm{O}_{3}$ with $\mathrm{Cs}_{2} \mathrm{O}$ contents $x=0.05,0.10$, and 0.20 . The difference spectra showed vanishing intensity at frequencies above $200 \mathrm{~cm}^{-1}$ but composition-dependent profiles below $150 \mathrm{~cm}^{-1}$. Analysis of these profiles using a deconvolution procedure applied to binary and ternary glasses ${ }^{60-63}$ showed the presence of two components; the $L$ band at 43 to $51 \mathrm{~cm}^{-1}$ and the $H$ band at 75 to $85 \mathrm{~cm}^{-1}$. Besides their small frequency reduction with decreasing Cs content, the relative intensity of the $L$ and $H$ bands depends strongly on glass composition. In particular, the $L$ band appears enhanced at low Cs contents indicating a favorable occupation of the low-frequency sites by the minority cations in the mixed-alkali glass. Since $H$ bands are associated with nbtype sites where NBOs play a vital role, the trend found in Fig. 10 is fully consistent with the Cs-NBO partial distribution function which looses intensity upon decreasing the Cs content [Fig. 3(d)].

While the far infrared profiles below $200 \mathrm{~cm}^{-1}$ were proven very informative for probing directly the composition dependence of Cs ion-oxide sites, a similar examination of the high-frequency region where the Li ion-oxide site vibrations are active is not straightforward. This is because the corresponding $\mathrm{Li}$ rattling bands have much larger band-

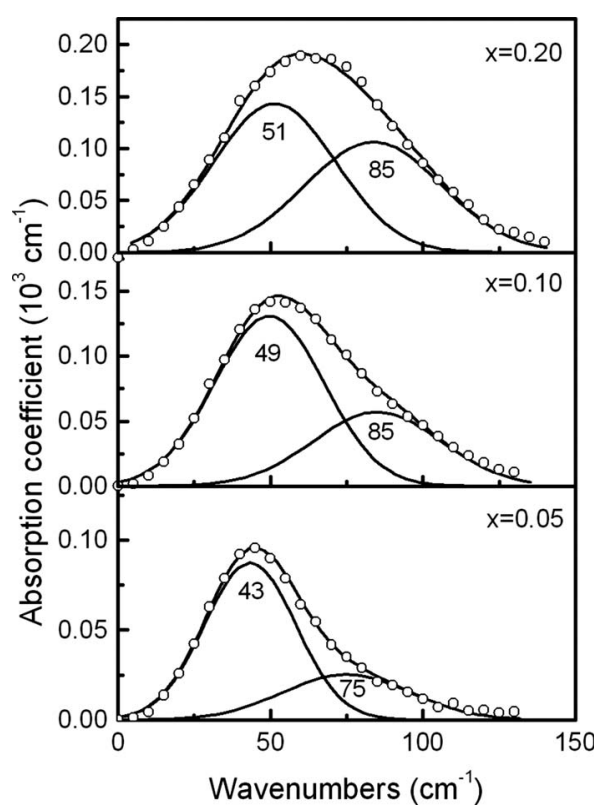

FIG. 10. Difference far infrared spectra (circle symbols) of glasses $0.33\left[(1-x) \mathrm{Li}_{2} \mathrm{O}-x \mathrm{Cs}_{2} \mathrm{O}\right]-0.67 \mathrm{~B}_{2} \mathrm{O}_{3}, \quad x=0.05, \quad 0.10$, and 0.20 , obtained by subtracting the far infrared spectrum of the binary glass $0.33 \mathrm{Li}_{2} \mathrm{O}-0.67 \mathrm{~B}_{2} \mathrm{O}_{3}$ ( $x=0.0$ in Fig. 9) from the corresponding spectra of the mixed Li-Cs glasses. Deconvolution of the difference far infrared spectra into Gaussian component bands is also included (solid lines).

widths as shown in Fig. 10. Nevertheless, earlier comparisons of experimental far infrared spectra of mixed-alkali glasses containing Li ions with those calculated as weighted averages of the binary glasses end-member spectra have shown that the Li ion-site interactions are strengthened with decreasing Li content. ${ }^{21-24}$ While this trend is obviously opposite to that found for $\mathrm{Cs}-\mathrm{O}$ interactions, it is in agreement with the behavior of the Li-O pair distribution functions in Fig. 3. In particular, the decrease in the average Li-O distance [Fig. 3(a)] with increasing Cs content appears to be related mainly to the increasing intensity of the Li-NBO partial and the increasing proximity of $\mathrm{Li}$ ions to NBOs [Fig. $3(\mathrm{c})]$.

Based on the trends found in Figs. 3(c) and 3(d) and the far infrared spectra in Figs. 9 and 10, it is of interest to explore the composition dependence of simulated Li ion- and Cs-ion-oxide site vibrational properties. To this aim, we have calculated the power spectra of $\mathrm{Li}$ and $\mathrm{Cs}$ ions in the vicinity of NBO atoms for the two end-member glasses $(x=0,1)$ and for the glass of maximum mixing $(x=0.5)$. We focus here on metal ions occupying nb-type oxide sites because they constitute about $90 \%$ of the total alkali population in mixed glasses, as seen in Fig. 5(a). The power spectra were obtained by calculating the Fourier transform of the velocity autocorrelation functions of $\mathrm{Li}^{\mathrm{nb}}$ and $\mathrm{Cs}^{\mathrm{nb}}$ ions $\mathrm{s}^{51-53}$ and are shown in Fig. 11(a) and 11(b), respectively. It is evident that the calculated spectrum of $\mathrm{Li}^{\mathrm{nb}}$ ions shifts to higher frequency in the mixed glass, in agreement with the shortening of the Li-NBO distance with alkali mixing (see Fig. 3(c)). On the other hand, the spectrum of $\mathrm{Cs}^{\mathrm{nb}}$ ions shifts to lower frequencies with mixing in full agreement with the experi- 


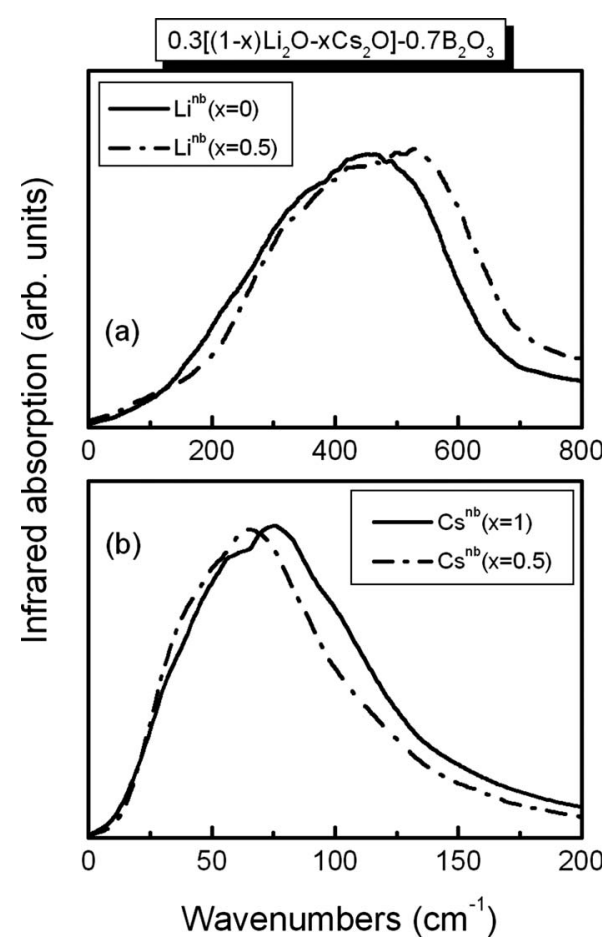

FIG. 11. Calculated power spectra at $T=300 \mathrm{~K}$ for $\mathrm{Li}$ ions (a) and for $\mathrm{Cs}$ ions (b) that occupy nonbridging type sites (denoted $\mathrm{Li}^{\mathrm{nb}}$ and $\left.\mathrm{Cs}^{\mathrm{nb}}\right)$ in simulated glasses $0.3\left[(1-x) \mathrm{Li}_{2} \mathrm{O}-x \mathrm{Cs}_{2} \mathrm{O}\right]-0.7 \mathrm{~B}_{2} \mathrm{O}_{3}$ for $x=0$ and $x=1$ (solid lines) and $x=0.5$ (dash dotted lines). For details see text.

mental far infrared spectra (Figs. 9 and 10), as well as with the lengthening of the Cs-NBO distance found in Fig. 3(d).

In view of the results reported in Fig. 6 and in Table II, the observed changes in metal ion-oxide site vibrational properties with alkali mixing can be attributed to formation of dissimilar ion pairs in the vicinity of NBOs. In fact, the pairing of dissimilar ions around an NBO atom has a probability of more than $85 \%$ for the $x=0.50$ glass in the Li-Cs system.

\section{CONCLUSIONS}

Mixed Li-Cs and Li-Na alkali borate glasses of composition $0.3\left[(1-x) \mathrm{Li}_{2} \mathrm{O}-x M_{2} \mathrm{O}\right]-0.7 \mathrm{~B}_{2} \mathrm{O}_{3}(M=\mathrm{Cs}$ and $\mathrm{Na})$ were investigated at room temperature by molecular dynamics simulations to elucidate the role of alkali mixing on glass structure. When the alkali cation mismatch is significant, i.e., for Li-Cs glasses, alkali mixing was found to have profound effects on the short-range order (SRO) structure as manifested by nonlinear deviations from additivity in the composition dependence of the fraction of borate tetrahedral, $\mathrm{B} \varnothing_{4}^{-}$, and of triangular units with $\mathrm{NBOs}, \mathrm{B} \varnothing_{2} \mathrm{O}^{-}$. On the contrary, no significant differences in the SRO structure were observed for glasses in the Li-Na system.

Examination of the alkali metal-oxygen $(M-\mathrm{O})$ and of the $M$-NBO RDFs in the Li-Cs system has shown that alkali mixing drives the higher-field strength cations (i.e., $\mathrm{Li}^{+}$) closer to oxygen atoms as both $\mathrm{Li}-\mathrm{O}$ and $\mathrm{Li}-\mathrm{NBO}$ distances decrease progressively with mixing, whereas the lower-field strength cations (i.e., $\mathrm{Cs}^{+}$) exhibit the opposite trend. The $\mathrm{Li}-\mathrm{O}$ and $\mathrm{Na}-\mathrm{O}$ RDFs for glasses in the Li-Na system remain practically unaffected by alkali mixing, while this is not the case for the $\mathrm{Li}(\mathrm{Na})-\mathrm{NBO}$ RDFs. As for Li-Cs glasses, the $\mathrm{Li}-\mathrm{NBO}$ and the Na-NBO distance decreases and increases, respectively, with alkali mixing despite the similarities in SRO structures of mixed $\mathrm{Li}-\mathrm{Na}$ glasses. These findings show that upon mixing, the metal ion-oxide interactions are strengthened for the higher-field strength cations and weakened for the lower-field strength cations.

Analysis of the types of metal ions present in the vicinity of NBO atoms has shown that the predominant configurations are those consisting of dissimilar cations for both glass systems investigated in this work. Specifically, the number of cations in aggregates around an NBO atom increases from 3 to 4 upon substituting $\mathrm{Li}$ by $\mathrm{Cs}$, while cations are present mostly in triads around NBOs for glasses in the Li-Na system. This is indeed an important finding of our work since it reveals a key structural basis for the origin of mixed-alkali effect (MAE), considering the predictions of the dynamic structure model for the blocking effect of dissimilar cations on the pathways for ion migration. Therefore, the preference of unlike-alkali pairing formation around NBOs upon mixing and the parallel drastic reduction in the number of NBOs that see like-cations, with a clear minimum at maximum mixing, provide a structural explanation for the MAE.

The existence of dissimilar cations in the vicinity of oxide anionic sites affects also the vibrational properties of alkali ions in their local sites. This was demonstrated by both experimental and simulated far infrared spectra of glasses in the mixed Li-Cs system. Thus, the far infrared profile associated mainly with Cs-O vibrations was found to shift progressively to lower frequencies in the mixed glasses indicating the weakening of the Cs-O interactions, while $\mathrm{Li}-\mathrm{O}$ interactions were found to exhibit the opposite trend.

\section{ACKNOWLEDGMENTS}

We acknowledge support of this work by the General Secretariat for Research and Technology, Greece, through programs "Excellence in the Research Institutes" (Phase I and II, Grants No. 64769 and No. 2005 EE01330081) and GreekFrench cooperation (Grant No. 042- 8 ).

\footnotetext{
*Corresponding author. FAX: 30-210 7273794; cvars@eie.gr

${ }^{1}$ J. O. Isard, J. Non-Cryst. Solids 1, 235 (1969).

${ }^{2}$ D. E. Day, J. Non-Cryst. Solids 21, 343 (1976).

${ }^{3}$ H. Jain and N. L. Peterson, J. Am. Ceram. Soc. 66, 174 (1983);

H. Jain, N. L. Peterson, and H. D. Downing, J. Non-Cryst. Solids 55, 283 (1983).

${ }^{4}$ G. Tomandl and H. A. Schaffer, J. Non-Cryst. Solids 73, 179 (1985).
} 
${ }^{5}$ M. D. Ingram, Phys. Chem. Glasses 28, 215 (1987).

${ }^{6}$ G. B. Rouse, E. I. Kamitsos, and W. M. Risen, J. Non-Cryst. Solids 45, 257 (1981).

${ }^{7}$ N. A. Sharaf, A. A. Ahmed, and A. F. Abbas, Phys. Chem. Glasses 39, 76 (1998).

${ }^{8}$ O. V. Mazurin, The Structure of Glass (Consultants Bureau, New York, 1965), Vol. 4, p. 5.

${ }^{9}$ J. Sakurai and K. Oaka, Toshiba Rev. 23, 913 (1968).

${ }^{10}$ J. R. Henrdickson and P. J. Bray, Phys. Chem. Glasses 13, 43 (1972); 13, 107 (1972).

${ }^{11}$ C. T. Moynihan, N. S. Saad, D. C. Tran, and A. V. Lesikar, J. Am. Ceram. Soc. 63, 458 (1980); M. D. Ingram, C. T. Moynihan, and A. V. Lesikar, J. Non-Cryst. Solids 38-39, 371 (1980); C. T. Moynihan and A. V. Lesikar, J. Am. Ceram. Soc. 64, 40 (1981).

${ }^{12}$ A. H. Dietzel, Phys. Chem. Glasses 24, 172 (1983).

${ }^{13}$ H. Kahnt and J. M. Reau, J. Non-Cryst. Solids 125, 143 (1990).

${ }^{14}$ G. B. Rouse, Jr., P. J. Miller, and W. M. Risen, J. Non-Cryst. Solids 28, 193 (1978).

${ }^{15}$ E. I. Kamitsos and W. M. Risen, J. Non-Cryst. Solids 65, 333 (1984).

${ }^{16}$ M. Misawa, D. L. Price, and K. Suzuki, J. Non-Cryst. Solids 37, 85 (1980).

${ }^{17}$ C. D. Hanson and T. Egami, J. Non-Cryst. Solids 87, 171 (1986).

${ }^{18}$ G. N. Greaves, Philos. Mag. B 60, 793 (1989).

${ }^{19}$ A. Bunde, M. D. Ingram, P. Maass, and K. L. Ngai, J. NonCryst. Solids 131-133, 1109 (1991); P. Maass, A. Bunde, and M. D. Ingram, Phys. Rev. Lett. 68, 3064 (1992); A. Bunde, M. D. Ingram, and P. Maass, J. Non-Cryst. Solids 172-174, 1222 (1994).

${ }^{20}$ E. I. Kamitsos, A. P. Patsis, M. A. Karakassides, and G. D. Chryssikos, J. Non-Cryst. Solids 126, 52 (1990).

${ }^{21}$ E. I. Kamitsos, A. P. Patsis, and G. D. Chryssikos, Phys. Chem. Glasses 32, 219 (1991).

${ }^{22}$ E. I. Kamitsos, J. Phys. IV 2, C2-87 (1992).

${ }^{23}$ E. I. Kamitsos, A. P. Patsis, and G. D. Chryssikos, in The Physics of Non-Crystalline Solids, edited by L. D. Pye, W. C. LaCourse, and H. J. Stevens (Taylor \& Francis, London, 1992), pp. 460465 .

${ }^{24}$ E. I. Kamitsos, A. P. Patsis, G. D. Chryssikos, and J. A. Kapoutsis, Chim. Chronica, New Ser. 23, 245 (1994).

${ }^{25}$ E. I. Kamitsos, Y. D. Yiannopoulos, C. P. Varsamis, and H. Jain, J. Non-Cryst. Solids 222, 59 (1997).

${ }^{26}$ P. W. S. K. Bandaranayake, C. T. Imrie, and M. D. Ingram, Phys. Chem. Chem. Phys. 4, 3209 (2002); M. D. Ingram, C. T. Imrie, and I. Konidakis, J. Non-Cryst. Solids 352, 3200 (2006).

${ }^{27}$ G. N. Greaves, The Physics of Non-Crystalline Solids, edited by L. D. Pye, W. C. LaCourse, and H. J. Stevens (Taylor \& Francis, London, 1992), pp. 453-459; G. N. Greaves and K. L. Ngai, J. Non-Cryst. Solids 172-174, 1378 (1994); Phys. Rev. B 52, 6358 (1995)

${ }^{28}$ J. Zhong and P. J. Bray, J. Non-Cryst. Solids 111, 67 (1989).

${ }^{29}$ P. J. Bray, J. F. Emerson, D. Lee, S. A. Feller, D. L. Bain, and D. A. Feil, J. Non-Cryst. Solids 129, 240 (1991); J. F. Emerson and P. J. Bray, ibid. 169, 87 (1994).

${ }^{30}$ R. K. Sato, R. J. Kirkpatrick, and R. K. Brow, J. Non-Cryst. Solids 143, 257 (1992).

${ }^{31}$ P. Florian, K. E. Vermillion, P. J. Grandinetti, I. Farnan, and J. F. Stebbins, J. Am. Chem. Soc. 118, 3493 (1996).
${ }^{32}$ E. Ratai, M. Janssen, and H. Eckert, Solid State Ionics 105, 25 (1998).

${ }^{33}$ J. D. Epping, H. Eckert, A. W. Imre, and H. Mehrer, J. NonCryst. Solids 351, 3521 (2005).

${ }^{34}$ J. Swenson, A. Matic, A. Brodin, L. Börgesson, and W. S. Howells, Phys. Rev. B 58, 11331 (1998); J. Swenson, A. Matic, C. Karlsson, L. Börgesson, C. Meneghini, and W. S. Howells, ibid. 63, 132202 (2001).

${ }^{35}$ L. Cormier, G. Calas, and B. Beuneu, J. Non-Cryst. Solids 353, 1779 (2007).

${ }^{36}$ M. Tomozawa and V. McGahay, J. Non-Cryst. Solids 128, 48 (1991); M. Tomozawa and V. McGahay, in The Physics of NonCrystalline Solids, edited by L. D. Pye, W. C. LaCourse, and H. J. Stevens (Taylor \& Francis, London, 1992), pp. 429-434.

${ }^{37}$ T. Uchino, T. Sakka, Y. Ogata, and M. Iwasaki, J. Non-Cryst. Solids 146, 26 (1992).

${ }^{38}$ A. Hunt, J. Non-Cryst. Solids 175, 129 (1994); 220, 1 (1997); 255, 47 (1999).

${ }^{39}$ S. D. Baranovskii and H. Cordes, J. Chem. Phys. 111, 7546 (1999).

${ }^{40}$ R. Kirchheim, J. Non-Cryst. Solids 272, 85 (2000).

${ }^{41}$ P. Maass, J. Non-Cryst. Solids 255, 35 (1999); P. Maass and R. Peibst, ibid. 352, 5178 (2006).

${ }^{42}$ V. Belostotsky, J. Non-Cryst. Solids 353, 1078 (2007).

${ }^{43}$ B. Vessal, G. N. Greaves, P. T. Martin, A. V. Chadwick, R. Mole, and S. Houde-Walter, Nature (London) 356, 504 (1992); W. Smith, T. R. Forester, G. N. Greaves, S. Hayter, and M. J. Gillan, J. Mater. Chem. 7, 331 (1997).

${ }^{44}$ S. Balasubramanian and K. J. Rao, J. Non-Cryst. Solids $\mathbf{1 8 1}$, 157 (1995).

${ }^{45}$ A. H. Verhoef and H. W. den Hartog, J. Non-Cryst. Solids 182, 235 (1995).

${ }^{46}$ J. Habasaki, I. Okada, and Y. Hiwatari, J. Non-Cryst. Solids 183, 12 (1995)

${ }^{47}$ J. Kieffer, J. Non-Cryst. Solids 255, 56 (1999).

${ }^{48}$ B. Park and A. N. Cormack, J. Non-Cryst. Solids 255, 112 (1999).

${ }^{49}$ C. Cramer, S. Brunklaus, Y. Gao, and K. Funke, J. Phys.: Condens. Matter 15, S2309 (2003).

${ }^{50}$ O. V. Mazurin, M. V. Streltsina, and T. P. ShvaikoShvaikovskaya, Handbook of Glass Data (Elsevier, New York, 1991), Part D, p. 2.

${ }^{51}$ C. P. E. Varsamis, A. Vegiri, and E. I. Kamitsos, Phys. Rev. B 65, 104203 (2002).

${ }^{52}$ A. Vegiri, C. P. E. Varsamis, and E. I. Kamitsos, J. Chem. Phys. 123, 014508 (2005)

${ }^{53}$ C. P. E. Varsamis, A. Vegiri, and E. I. Kamitsos, Phys. Chem. Glasses 47, 419 (2006).

${ }^{54}$ M. A. Gonzalez, C. Mondelli, G. D'Angelo, C. Crupi, and M. R. Johnson, J. Non-Cryst. Solids 354, 203 (2008).

${ }^{55}$ F. G. Fumi and M. P. Tosi, J. Phys. Chem. Solids 25, 31 (1964).

${ }^{56}$ A. Vegiri and C. P. E. Varsamis, J. Chem. Phys. 120, 7689 (2004).

${ }^{57}$ E. I. Kamitsos, C. P. E. Varsamis, and A. Vegiri, Proceedings of the 19th International Congress on Glass, Edinburgh (Society of Glass Technology, Sheffield, UK, 2001), Vol. 1, pp. 234-246.

${ }^{58}$ U. Schoo, C. Cramer, and H. Mehrer, Solid State Ionics 138, 105 (2000)

${ }^{59}$ A. W. Imre, S. Voss, and H. Mehrer, J. Non-Cryst. Solids 333, 231 (2004). 
${ }^{60}$ E. I. Kamitsos, A. P. Patsis, and G. D. Chryssikos, J. Non-Cryst. Solids 152, 246 (1993).

${ }^{61}$ E. I. Kamitsos and G. D. Chryssikos, Solid State Ionics 105, 75 (1998).
${ }^{62}$ E. I. Kamitsos, Y. D. Yiannopoulos, H. Jain, and W. C. Huang, Phys. Rev. B 54, 9775 (1996).

${ }^{63}$ C. P. Varsamis, E. I. Kamitsos, and G. D. Chryssikos, Phys. Rev. B 60, 3885 (1999). 